\title{
MEDIOS DE COMUNICACIÓN Y CIUDADANÍA
}

Faride Zerán Chelec 


\section{FARIDE ZERÁN CHELECH}

Periodista de la Universidad de Chile. Premio Nacional de Periodismo en 2007. Entre 1997 y 2003 fue Directora de la Escuela de Periodismo de la misma Universidad. En 2003 fue la primera Directora del Instituto de la Comunicación e Imagen (ICEI) fundado bajo su dirección. Entre el 2000 y 2004 fue integrante del Directorio de TVN. Fue fundadora y Directora de la revista cultural Rocinante (1998-2005). Hoy en día es profesora titular del ICEI de la Universidad de Chile. 


\section{MEDIOS DE COMUNICACIÓN Y CIUDADANÍA}

La ciudadanía consiste en la titularidad y ejercicio de los derechos civiles, políticos, sociales y culturales, incorporando a ella la demanda de los nuevos movimientos sociales que irrumpen en la esfera pública y que nos hablan de reclamos provenientes de movimientos étnicos, de género, etarios, minorías excluidas o mayorías marginadas del sistema. En este contexto, al analizar la visibilidad de estas demandas en la agenda pública o en el debate mediático, así como el tratamiento de estos temas y la forma como emergen estos nuevos protagonistas en los medios, en el caso chileno la reflexión es compleja. Particularmente, porque tan solo en la descripción de ciudadanía el periodismo tradicional queda atrapado en la estrechez de conceptos como fuentes o noticia circunscribiendo su eje a los llamados "frentes noticiosos": Tribunales, Palacio de Gobierno, Congreso, Fuerzas Armadas, organismos empresariales, Iglesia, partidos políticos y organismos económicos, por nombrar los más comunes. Todo el resto va a una suerte de "cajón de sastre" que alimenta las secciones que algunos medios llaman "Crónica" y otros "Nacional".

De ahí que si lo público ha sido considerado como todo aquello que emana de fuentes oficiales, lo otro no solo no es clasificable, sino que además corre el riesgo de que no sea considerado noticia, ya que según los cánones tradicionales la noticia no es generada por el ciudadano común, a menos que sea víctima o verdugo de algo.

En Chile, desde los inicios de la transición a la democracia, cuando se suponía que quedaba atrás la secuela de férrea censura del régimen de Pinochet, muchos estudios han dado cuenta del malestar ciudadano hacia los medios de comunicación masivos, tanto por la ausencia de cobertura periodística, que definitivamente ignoraba -y lo sigue haciendo- determinados hechos, o bien su comportamiento ante la forma de abordar ciertas noticias consideradas relevantes, pero cuyo tratamiento despertaba suspicacias o simplemente irritación. Eran los años de la premisa de justicia, pero también democracia y libertad "en la medida de lo posible", que a inicios de los 90 sancionó al periodismo independiente por no aceptar las reglas tácitas de que la transición exigía, y una de ellas era la libertad de expresión, como lo ilustra ampliamente el libro de Human Rights Watch, Los límites de la tolerancia. Libertad de expresión y debate público en Chile.

La Premio Nacional de Periodismo 2009, María Olivia Mönckeberg, en el prólogo de su libro Los magnates de la prensa. Concentración de los medios de comunicación en Chile (2008), confiesa la frustración generada por este escenario comunicacional para toda una generación de profesionales de la prensa: "Desde hace ya dos décadas, al terminar la dictadura, muchos periodistas de mi generación advertíamos que la concentración de los principales medios de comunicación y sus vinculaciones con el poder político y económico constituían motivos de inquietud para el tiempo que venía. La anhelada libertad de expresión y la propia democracia que pretendíamos reconstruir podía estar amenazada". Y señala a continuación: "Las voces de alerta no tuvieron eco. Y los consorcios que 
habían sido sólidos puntales de apoyo del gobierno militar -y salieron de sus deudas con el respaldo del Estado antes de que Augusto Pinochet dejara La Moneda- dominaron la escena posdictatorial. Captaron gran parte de la publicidad de la prensa escrita, mientras las revistas y diarios que lucharon por la democracia desaparecieron uno tras otro del escenario. Tampoco fueron "viables" los esfuerzos que algunos levantaron después para generar un periodismo escrito independiente de los grupos económicos". Dejar hacer al "mercado" en este terreno -concluye Mönckeberg-, "solo ha contribuido a consolidar a los grupos de poder dueños de los principales medios tanto escritos como audiovisuales. Y hasta la radio, tradicionalmente considerada plural y diversa, muestra hoy síntomas de concentración en grandes cadenas, adonde llegan también las redes del denominado duopolio".

\section{LA INFORMACIÓN EN TANTO DERECHO CIUDADANO}

Sin embargo en el siglo XXI, con las grandes manifestaciones ciudadanas que en el segundo semestre del 2011 han sacudido al país, volcando a las calles y plazas a cientos de miles de manifestantes reivindicando derechos medioambientales, de parejas del mismo sexo, o en pos de una educación pública de calidad, la relación entre esa ciudadanía empoderada y los grandes medios no solo se tensó. Además obligó a estos últimos a revisar sus rutinas y lenguajes profesionales.

Porque si antaño la libertad de expresión y el derecho a la información eran asumidos como propios del periodismo, hoy la percepción ha cambiado. Por primera vez en décadas la información es incorporada como derecho ciudadano y, en tanto derecho, sujeta a estándares de veracidad y pluralismo que cada ciudadano empoderado puede fiscalizar. En medio de esta dinámica política, social y comunicacional, las redes sociales de Internet -Facebook, Twitter- aparecen como los grandes propulsores del cambio al conectar las frustraciones y anhelos simultánea y democráticamente, sin líneas editoriales y menos censuras previas que sortear. De ahí el entusiasmo que genera entre analistas políticos y estudiosos de la comunicación del mundo occidental el rol de estas redes sociales en "la primavera árabe", que barrió con los regímenes autocráticos de Zine El Abdine Ben Alí, en Túnez, y de Hosni Mubarak, en Egipto, a inicios del 2011, y aún mantiene en vilo a la comunidad internacional que paralelamente a la intervención europea en Libia, sigue con impotencia la brutal represión desatada en Siria por las fuerzas del régimen de Bachir al-Assad.

Pero, desde un contexto de análisis del rol de los medios, si bien la existencia de una juventud con altos índices de escolaridad en los casos anteriores, pero con igual tasa de desempleo, fueron el detonante -junto al asesinato de un joven tunecino- para una de las rebeliones ciudadanas más interesantes de los últimos tiempos, no son solo las redes sociales fueron las que ayudaron a romper el cerco informativo en esos países y a organizar e informar a la masa descontenta. Para muchos expertos que han estudiado las revoluciones del Magreb y Medio Oriente, el papel de la cadena de televisión Al Jazeera ha sido fundamental en la entrega de información desde una perspectiva regional y a la 
vez independiente de los intereses de los gobernantes locales, lo que no significa reemplazar la decisión y movilización ciudadana que con su malestar resultan ser el principal motor de cambio.

Sin embargo, hay ejemplos más cercanos de desfase entre información y ciudadanía. Una de las constantes de la sociedad chilena de las últimas tres décadas ha sido la alta concentración de la prensa escrita en un duopolio, la cadena El Mercurio y Copesa, que reúnen el $85 \%$ de la propiedad de los diarios y revistas que circulan en el país. En la investigación efectuada a inicios del 2000 por los académicos Rafael Otano y Guillermo Sunkel, "La libertad de los periodistas en los medios", del Programa de Libertad de Expresión del Instituto de la Comunicación e Imagen (ICEI) de la Universidad de Chile, se señalaban los vicios del ejercicio del periodismo en la transición chilena, y que aún hoy constituyen patrones vigentes. Por ejemplo, el periodismo en "piño" entendido como aquel que hace de los frentes noticiosos estables la columna vertebral de la pauta de los medios.

De esta manera, los frentes o las fuentes se repiten hasta el infinito: ejecutivo, policía, tribunales, partidos políticos, etcétera, lo que sumado al abuso de las conferencias de prensa, donde se entrega la verdad pulida y oficial, el panorama aparece como desalentador y plano, pero también como propicio para atentar contra los derechos de las personas. Si ese ciudadano o ciudadana común es pobre, es indígena o es parte de una minoría sexual, tenderá a aparecer en los medios solo en la gama de estereotipos ya ensayados, en aquello "conocido": en tanto sujeto delictual, subversivo o escandaloso; o con el agua al cuello pidiendo ayuda, en el caso de los marginados del sistema, y en tanto "violentista" incendiando fundos, como ocurre con las demandas del pueblo mapuche. Si sumamos a este contexto la irrupción del periodismo light, con su apuesta por la banalización de todo discurso, la saturación del periodismo de espectáculo, que no es otra cosa que la subordinación de la noticia al mercado, constatamos que estamos ante prácticas profesionales que se contraponen a lo que podríamos denominar un periodismo ciudadano, o bien un periodismo público.

Esta definición asume como premisa central que en una sociedad democrática los medios cumplen el papel de socializar los debates, los argumentos y contraargumentos, y son fundamentales para contribuir a la formación de una voluntad colectiva que se expresa en interés público. ¿Cuál es el papel de los ciudadanos en una democracia? ¿Cuál es el rol de los periodistas? ¿De qué manera coinciden estos dos roles? Estas son algunas de las interrogantes que se plantea el periodismo público y que tienden a la idea de reconectar a los ciudadanos con la vida pública, potenciar la capacidad de deliberación de la ciudadanía, ofrecer información con miras a la participación, apoyar los procesos ciudadanos con una buena cobertura y, especialmente, un adecuado seguimiento, al tiempo que pone a los medios en calidad de actores y promotores del diálogo social.

Con esta definición no solo el concepto de noticia o la naturaleza de las fuentes son trastocadas, sino la famosa "objetividad", entendida como neutralidad frente a los hechos, y que por décadas se ha entronizado en la formación de los periodistas universitarios. De modo que si en el periodismo público la información es entendida como un bien público, y surge de la preocupación por mejorar la calidad de la vida de la 
comunidad para darle contenido al compromiso de los medios de comunicación con la democracia y la vida colectiva, el periodismo light tiene su fundamento en el deseo de algunos medios de aumentar sus ventas.

En síntesis, en el periodismo público los periodistas no son neutrales, están al servicio de la democracia, asumiéndola en su más amplia acepción y sin hacer concesiones en su rol crítico, distante y fiscalizador de todos los poderes. A la vez es capaz de ampliar su mirada para incorporar en sus pautas y análisis, no solo lo que ocurre en el centro de la polis, sino que también lo que ocurre en sus márgenes, contribuyendo con su quehacer al encuentro ciudadano a través del diálogo cívico, donde nadie sobra. Se trata de un nuevo contrato profesional entre el periodista y la ciudadanía que requiere que ambas partes estén conscientes de sus derechos:

El periodista ha de ejercer su profesión en un país sin restricciones a la libertad de expresión, en el que el acceso a la información pública no solo constituya una norma sino una práctica que acabe con el secretismo de nuestra sociedad. Donde los sujetos, los movimientos sociales y los nuevos actores emergentes que irrumpen sean fuentes de información y análisis, validadas tanto o más que aquellas fuentes oficiales que homogenizan y empobrecen al país.

En el caso de la ciudadanía, este nuevo contrato implica exigir su derecho a estar informada oportuna y verazmente -sin censuras-, y a través de medios capaces de reflejar el pluralismo y la diversidad política y cultural que la enriquecen.

\section{DE DUOPOLIO INFORMATIVO A DUOPOLIO IDEOLÓGICO}

Sin embargo, poco o nada de todo esto ocurre en el Chile actual, donde a la concentración de la prensa escrita, en el duopolio El Mercurio-Copesa, se suman otros fenómenos que atentan contra la libertad de expresión.

Uno de ellos es la constatación de que si bien el proceso de concentración económica de medios no es un fenómeno típicamente chileno, como dicen Guillermo Sunkel y Esteban Geoffroy en el libro La concentración económica de los medios de comunicación en Chile, publicado el 2001, nuestra dramática peculiaridad está en que dicho proceso va acompañado por un "marcado monopolio ideológico", especialmente en la prensa escrita, y que la causa de la falta de diversidad se encuentra en el empresariado chileno. En el mismo estudio ambos autores afirman que "la tendencia a la concentración de los avisos publicitarios en unos cuantos medios de prensa, radio y televisión no muestra señales de cambio. Ello principalmente debido a ciertas características del empresariado chileno. Se trata de un empresariado ideológicamente homogéneo, educado en una matriz económica neoliberal y en un conservadurismo valórico donde quienes se salen de este esquema constituyen excepciones a la tendencia general. Y esto incluye no solo a los propietarios de los medios sino también al conjunto de los avisadores".

En esta línea, los académicos Osvaldo Corrales y Juan Sandoval señalaban, en otro trabajo llamado "Concentración del mercado de los medios, pluralismo y libertad de expresión", publicado el 2005, que el tradicional concepto de oligopolio no resulta 
suficiente para comprender la forma en que se ha estructurado el mercado de la prensa chilena. "Una característica del empresariado nacional es su alto nivel de uniformidad ideológica, que en lo económico se expresa en un compromiso con el modelo neoliberal, y en lo cultural en un fuerte conservadurismo valórico, de modo que cuando actúan como avisadores utilizan la inversión publicitaria como una herramienta para fortalecer aquellos medios que les son más afines, introduciendo una distorsión en el mercado que dificulta la aparición de otras expresiones". Más adelante puntualizan que "estrechamente vinculado con lo anterior surge una segunda forma de intervención sobre los medios que se traduce en las presiones que ejercen cuando los contenidos que se difunden pueden comprometer, directa o indirectamente, los intereses corporativos de algunos avisadores".

Una de las advertencias contenidas en ese trabajo no resulta indiferente en el Chile actual, ante el divorcio que se manifiesta entre las demandas ciudadanas y la cobertura que los grandes medios le otorgan. Ambos investigadores concluyen que las limitantes de los medios en cuanto a pluralismo están fuertemente ligados al monopolio ideológico, puesto que al estar la esfera pública restringida a los intereses de los actores dominantes del mercado, hay una invisibilización de los contenidos específicos que se opongan a los intereses de estos últimos. En el estudio "Mordazas de la Transición", editado por el Instituto de la Comunicación e Imagen de la Universidad de Chile, y que contiene varias investigaciones de su Programa Interdisciplinario de Libertad de Expresión, se señala entre los indicadores regresivos de la transición a la democracia los siguientes puntos que corroboran lo anteriormente señalado: "La desaparición de diarios y revistas que se distinguieron por su impulso antiautoritario; la consolidación, en la prensa escrita, del duopolio favorito del régimen militar formado por El Mercurio y Copesa; el predominio abrumador de medios ultraliberales en lo económico e integristas en lo moral que de ninguna manera responden a la gama completa de ideas y tendencias del conjunto de la población".

¿De qué forma, entonces, pueden consolidarse en el Chile del siglo XXI los medios independientes que propongan otra pauta informativa, incorporando otros sujetos a la agenda pública y oponiendo al estereotipo y la estigmatización de los nuevos sujetos sociales una mirada más diversa, plural y tolerante? ¿Más cuando al sesgo ideológico del empresariado chileno, léase los avisadores de los medios, se une aquella que exhiben las empresas del Estado, cuyo 77 \% de su inversión publicitaria beneficia directamente a El Mercurio y Copesa, de acuerdo a un estudio realizado en el año 2005 por Fucatel? Que Chile ocupara en el registro del 2005 el lugar número 50 de la clasificación mundial de libertad de expresión, según Reporteros sin Fronteras, entre Mozambique y República Dominicana, no es un detalle menor. Como tampoco que durante los cuatro gobiernos de la Concertación estos se resistieran a asumir el déficit de pluralismo informativo como un tema de Estado, y no de mercado, normando a través de políticas públicas, por ejemplo, que un porcentaje de la publicidad de sus empresas fuera a los medios independientes, corrigiendo en algo el déficit de diversidad y pluralismo que aqueja a nuestra sociedad.

Un ejemplo paradigmático fue lo acontecido en el 2004, cuando La Nación domingo tituló su portada con un reportaje sobre el dueño de la cadena de supermercados 
Líder, Nicolás Ibáñez, como "La otra cara del Líder", aludiendo a las acusaciones de violencia intrafamiliar efectuada por su ex esposa, más otros testimonios que hablaban de un doble discurso de este empresario, miembro de Los Legionarios de Cristo. Pero esa edición dominical no llegó de manera normal a sus lectores, pues fue recogida en todo el país a través de personal movilizado en camiones del empresario aludido, los que durante la madrugada "compraron" la edición completa. Tuvo que transcurrir casi una semana de este hecho para que Televisión Nacional de Chile finalmente emitiera la nota reporteada oportunamente, luego de reiterados reclamos y presiones de distintos sectores ciudadanos.

Pero esta información, que constituía una flagrante violación a la libertad de expresión, fue silenciada durante casi una semana en los grandes medios escritos, y solo días más tarde apareció en una nota muy reducida y en las páginas de la sección económica.

En un Seminario sobre Comunicación y Pobreza, organizado en el 2008 por la Fundación de la Superación de la Pobreza, el Hogar de Cristo, y la Escuela de Periodismo de la UDP, se dio a conocer una encuesta ciudadana sobre Exclusión y Medios de Comunicación. En ese marco se presentó el libro Voces de mujeres. Historias de vida en primera persona, donde once mujeres de distintas edades y comunas de la Región Metropolitana hablan sobre lo que es ser, vivir y sentirse pobre en un ejercicio de introspección que refleja la valentía y dignidad con que asumen la miseria. En dicha encuesta, la mala noticia para los periodistas es que los medios de comunicación fueron reprobados con una nota 3,9 , por el tratamiento que hacen de la pobreza en tanto muestran a los pobres como delincuentes. Este estereotipo tiene como correlato a las propias protagonistas del libro. Para Bernarda, en los medios a los pobres los muestran a la pinta de ellos. "Ellos quieren tener harto rating y no miran las consecuencias que puedan producir", añade Bernarda. Mercedes, en tanto, se pregunta: " $-i$ Te has fijado que cuando ocurre un drama en una familia pobre, van todos los periodistas encima de esa familia, y cuando ocurre un drama similar a la gente de estrato más alto, ¿por qué no los invaden como a la gente pobre?"

Esta encuesta y las voces de estas mujeres que además exigen de los medios, no solo respeto hacia sus vidas, sino un mayor rol de la televisión en programas culturales y educativos, nos hablan de un malestar hacia los medios y periodistas, y de una demanda ética acerca del tratamiento de la información, la veracidad de la misma, y sus consecuencias en tanto son los propios medios quienes se instalan como activos agentes de estigmatización y exclusión social. Al respecto, otra muestra de fines del 2007 entregada en el marco de un debate sobre la ética convocada por el Colegio de Periodistas: se trataba de una encuesta sobre percepción ciudadana de periodistas y medios de comunicación, elaborada por La Tercera, donde aparece que solo un 45 \% de la población señala que los periodistas informan con rigurosidad siempre o casi siempre. Más aun: menos de la mitad de las personas cree que somos serios y rigurosos en lo que determina nuestro quehacer. Y ante la pregunta de si ejercemos con ética nuestro trabajo, el $50 \%$ señala que algunas veces, casi nunca o nunca.

En el mismo sondeo, efectuado a fines del 2007, un 58 \% de los encuestados concuerdan que los periodistas pueden hacer más, pero se autocensuran, señalando también que los periodistas que publicitan productos o servicios de empresas pierden credibilidad. 
Tanto la encuesta de la Fundación para la Superación de la Pobreza, como la del de diario La Tercera efectuada para el Colegio de Periodistas, resultan interesantes como punto de partida de un debate sobre información y ciudadanía. De allí proviene la preocupación de las escuelas de periodismo serias, en el sentido de ver de qué manera fortalecemos y actualizamos la formación ética de las nuevas generaciones de periodistas nacidos en la era de Internet y de la revolución tecnológica; nuevas generaciones que a veces asumen esas herramientas como instrumentos vacíos e inocuos, sin extrapolar preceptos básicos como la verificación de las fuentes, el derecho a la intimidad y a la dignidad de las personas, la investigación in situ, los contextos, la jerarquización de los hechos, etcétera. Pero la pregunta por la ética en el periodismo es la interrogante por la credibilidad y veracidad de su información, por la calidad de sus fuentes, la independencia de sus periodistas y el pluralismo y libertad de sus contenidos.

Otro ejemplo sobre la construcción de estereotipos en los medios es el estudio "Cobertura y Tratamiento de la Infancia Mapuche en la prensa de la región de la Araucanía" del Instituto de la Comunicación e Imagen de la Universidad de Chile y la UNICEF, sobre las representaciones de la infancia mapuche en la prensa de la Región de la Araucanía. Una de sus principales conclusiones es la escasa presencia que tienen los niños y adolescentes mapuche en los medios de comunicación. Solo el 1,9 \% de las noticias publicadas se refieren a temas vinculados con infancia mapuche, y más del $50 \%$ de ellas apenas ocupa un sexto de página.

Pero más que las cifras, la respuesta de un periodista encuestado para este trabajo revela esta discriminación: "...Si me dices mapuche hoy, yo digo violencia, exigencias, desprotección. Son términos que se me vienen a la mente, lo que nosotros consideramos al abordar los temas mapuches..."

\section{EL FIN DEL PERIODISTA O "VER NO ES COMPRENDER".}

Acerca de la extinción de la figura del periodista como consecuencia de la irrupción de las nuevas tecnologías, particularmente a través de Internet, es bueno recordar el estudio de WIP y de la Universidad Católica efectuado hace un par de años, donde se señala que solo el 43 \% de los hogares chilenos tiene computador. Si para Umberto Eco la función del cuarto poder es la de controlar y criticar a los otros tres poderes tradicionales, como lo expresa en su ensayo "Sobre la prensa", para el periodista argentino Horacio Verbitsky la función de la prensa no es jugar con la verdad virtual ni propiciar paraísos artificiales. La información, señala Verbistsky en su libro Un mundo sin periodistas, no es un privilegio de los periodistas sino un derecho de los pueblos, y la mejor contribución al afianzamiento de una cultura democrática reside en decir la verdad de los hechos. Pero, sin duda no constituye el único reto o desafío.

Otro es lo que Eco denomina algo así como la televisación de la prensa, aquella que es esclava de la televisión, que a fuerza de competir con ella eleva todo al sentido del espectáculo. La que es capaz de alargar lo que no es noticia y eliminar aquella que, 
siéndolo, sencillamente no vende, lo que junto a la pérdida de lectores la hace perder credibilidad. Y ejemplos al respecto sobran.

En Estados Unidos, según Ignacio Ramonet, el 55 \% de los ciudadanos estima que los medios de comunicación escritos publican informaciones con frecuencia inexactas. Para Ramonet, estamos en medio de la era de la sospecha, en tanto la información entra de lleno en la lógica del espectáculo, en un fenómeno que se impone en la televisión pero del cual no es ajena la prensa escrita. Esto, en un contexto de superabundancia de información y donde la imagen directa de los hechos transmitidos por la televisión nos remite a la ilusión de que sabemos todo y sin filtros, sin asumir que "ver no es comprender" y que, paradojalmente, nunca habíamos estado tan desinformados. Esto condensa la demanda por un periodismo serio, ético, capaz de entrar en los temas diarios de la gente, en los abusos que se cometen en su nombre, en sus viviendas indignas, en sus salarios precarios, en la falta de oportunidades para los jóvenes o en la mala educación.

Noticia es también el relato de cómo se vive cotidianamente en un campamento de pobladores, manteniendo las mediaguas impecables y los hijos limpios y bien peinados, porque la pobreza tiene varias caras. Y una de ellas es la dignidad.

Es discernir entre el significado de las manifestaciones ciudadanas pacíficas y las infiltraciones que esos movimientos puedan exhibir.

Es interrogarse por qué los ciudadanos y ciudadanas, los estudiantes, los profesores se toman las calles y plazas de todo el país, y no banalizar o estereotipar sus reivindicaciones.

Es Bernarda contando su niñez en Paillaco, y el dolor de sentirse discriminada porque su padre es mapuche.

A ese periodismo la ciudadanía apuesta sin reservas. Mientras no exista, las redes sociales seguirán apuntando al déficit de información y, por ende, de democracia del Chile del Bicentenario.

\section{REFERENCIAS BIBLIOGRÁFICAS}

Corrales, Osvaldo y Sandoval, J., "Concentración del mercado de los medios, pluralismo y libertad de expresión", en Documentos del Cecom-ICEI, 2005, pág. 99.

Eco, U., Cinco escritos morales, Barcelona: Lumen, 1998.

Echauz, Pau y Pisani, Francis, "Twitter no sirve para tomar el poder", en La Vanguardia Digital, 11 abril 2011, véase: http://www.lavanguardia.com/vida/20110411/54138785443/francispisani-twitter-no-sirve-para-tomar-el-poder.html

Human Rights Watch, Los límites de la tolerancia. Libertad de expresión y debate Público en Chile, Santiago de Chile: LOM Ediciones, 1998.

Labrín, Cabalín y Lagos, "Cobertura y Tratamiento de la Infancia Mapuche en la prensa de la región de la Araucanía", ICEI-UNICEF, Marzo 2008.

Mönckeberg, $\mathrm{M}^{a} \mathrm{O}$., Los magnates de la prensa. Concentración de los medios de comunicación en Chile, Santiago de Chile: Debate, 2008, pág. 9.

"Mordazas de la Transición" del Programa de Libertad de Expresión 1999-2001, Santiago: ICEI, 2005. 
Revista Comunicación y Medios-ICEI-Marzo 2003.

Sunkel, Guillermo y Geoffroy, Esteban, La concentración económica de los medios de comunicación en Chile, Santiago de Chile: Ediciones LOM, 2001, pág. 110.

Verbitsky, H.,Un mundo sin periodistas, Planeta: Buenos Aires, 1997.

Voces de Mujeres. Historias de vida en primera persona. Comunicación y pobreza de la Fundación Superación de la Pobreza, Santiago: Ediciones UDP-Universidad Católica Silva Henríquez, 2008, págs. 18-19. 